\title{
19
}

\section{The Perceptions of Stakeholders in Low Impact Development Planning}

\author{
Sarah O. Lawson, Darko Joksimovic, James Y. Li \\ and Michael Walters
}

As part of measures to mitigate the impact of contaminants on Lake Simcoe, a project is being carried out by the Lake Simcoe Region Conservation Authority (LSRCA) to identify opportunities for the implementation of low impact development (LID) technologies throughout the watershed. Stakeholder engagement has been a strong element since the initiation of the project as demonstrated through various activities carried out by the LSRCA. Building upon these activities, the research study presented in this chapter provides further insight into the current opinions of and the concerns about stormwater management regarding LID practices held by traditional stakeholders. Questionnaires were distributed on three occasions to collect the opinions of specific stakeholder groups regarding LID planning in the Lake Simcoe watershed. The results indicated that traditional stakeholders are supportive of widespread LID implementation; however there are significant concerns and perceptions that must be addressed by proponents of LID. Finally, the conclusions of this research study demonstrate that the involvement of stakeholders from the beginning of the LID planning process is a necessary requirement to facilitate long term successful LID application throughout the watershed.

\subsection{Introduction}

In the past few decades, emphasis has been placed on involving stakeholders in environmental planning, decision making and policy development (Beers,

Lawson, S., D. Joksimovic, J. Li and M. Walters. 2011. "The Perceptions of Stakeholders in Low Impact Development Planning." Journal of Water Management Modeling R241-19. doi: 10.14796/JWMM.R241-19. (C) CHI 2011 www.chijournal.org ISSN: 2292-6062 (Formerly in Cognitive Modeling of Urban Water Systems. ISBN: 978-0-9808853-4-7 
1973, cited in Adams, Dove and Leedy, 1984; Beierle and Konisky, 2000; Larson and Lach, 2007). The practice of stormwater management has been no exception to this concept and has evolved accordingly to include stakeholder participation in the planning and decision-making process. It has been recognized that sustainable solutions to stormwater pollution are only achievable with the involvement of all affected parties (Lloyd et al., 2002; Ellis et al., 2004; Apostolaki et al., 2006; Brown and Farrelly, 2008; Roy et al., 2008). As Beers (1973, cited in Adams et al., 1984) pointed out, "the success of any program to manage runoff as a water resource in the suburban environment is highly dependent upon the support of the people in that environment." This view holds true in the application of low impact development methods of stormwater management.

The intention of LID practices is to preserve the predevelopment hydrology of a site (Dietz, 2007) by controlling rainfall onsite (Gilroy and McCuen, 2009; Prince George's County, Maryland, 1999) and through conveyance systems that discharge to downstream watercourses (Graham et al., 2004). Achieving this objective has included targeting the reduction of volume and rate of surface runoff from development or redevelopment sites. LID devices include structural practices such as swales, rainwater harvesting tanks, bioretention units, and filter strips (Elliott and Trowsdale, 2006). Nonstructural measures include the clustering of houses, alternate layouts of roads and buildings to minimize imperviousness, and programs of education (Elliott and Trowsdale, 2006).

Due to the nature of these technologies, the requirement to involve a range of groups representing various interests, socially, technically and politically, is essential for effective LID application. Governments and organizations worldwide have acknowledged the integrated planning and design process and the requirement to involve a range of disciplines (Government of British Columbia, 2002; Brown, 2005; Ellis et al., 2006; SEMCOG, 2008; CVC and TRCA, 2009). In order to achieve long term support for a stormwater management scheme, commitment to the project by key stakeholder groups such as local government, the local water authority and stormwater practitioners, is required. In addition, beyond the traditional stakeholders of stormwater management, successful LID implementation requires the involvement of a wider group such as elected officials, landscape architects and representatives from the community, in the planning stages (SEMCOG, 2008). Without the support of all affected groups, other issues can arise such as jurisdiction complications, lack of participation, and ineffective implementation (SEMCOG, 2008).

Gaining the support of all affected groups is of particular importance when planning for LID implementation on a watershed level. Several papers 
have documented the existing challenges on widespread LID adoption (Lloyd et al., 2002; Ellis et al., 2004; Brown 2005; Roy et al., 2008). In particular, Roy et al. (2008) provides a discussion on impediments associated with LID implementation on a watershed-scale; the authors claim that in order to achieve sustainable stormwater management, one fundamental element is that it must be planned and applied on a watershed scale. To attain effective implementation, consistent institutional, legislative, economic and social arrangements must be applied across an entire watershed. In the context of this discussion, impediments such as resistance to change will continue to remain a barrier that proponents struggle to overcome if a consistent approach is not taken to engage and educate stakeholders on a wider scale.

Involving stakeholders from the initial stages of LID planning will mitigate a significant amount of resistance to implementation issues and lead to widespread support. This is demonstrated by existing research studies in countries such as Australia ( Eadie, 2002, and Mongard, 2002, cited in Roy et al., 2008; Lloyd et al., 2002; Brown and Clarke 2007; Brown and Farrelly, 2008), the United Kingdom (McKissock et. al., 1999, and Hjerpe and Krantz, 2000, cited in Apostolaki, 2006; McKissock et. al., 2003; Apostolaki, 2006), France (Ellis et. al., 2004), and Canada (Hwang et al., 2006; Farahbakhsh et al., 2008), which have investigated the role and importance of stakeholder involvement in LID implementation.

\subsection{Lake Simcoe Case Study}

The principles of stakeholder participation have been applied in a LID planning project carried out in the Lake Simcoe watershed region in Ontario, Canada. Through water quality monitoring activities throughout the watershed, the LSRCA has identified that the Lake Simcoe watershed is impacted by many contaminants, particularly phosphorus. The overall aim of the Lake Simcoe LID project, which was initiated in April 2009, is to identify opportunities for the implementation of LID technologies. In addition to this, the project seeks to quantify, at a planning level, the benefits that could be provided in terms of reduced pollutant loading to Lake Simcoe from areas that have been identified as not being suitable for retrofitting conventional stormwater management practices (Li et al., 2009).

A number of activities to engage stakeholders in the LID planning process have been completed to date. The project leaders have identified various methods in which stakeholder engagement can occur. For example, while the study is being managed by the LSRCA and being carried out by a team of researchers from Ryerson University, a steering committee has been set up 
to guide the progress of the study and to ensure that a meaningful outcome is obtained for watershed stakeholders. The members of the steering committee consist of representatives of municipalities within the watershed, officials from various levels of governments, the research team, and employees of LSRCA.

In addition to the participation of stakeholders with direct and immediate interests in the Lake Simcoe region LID planning study, a workshop (the Phase 1 Workshop for Stormwater Management Strategies for Uncontrolled Urban Areas in the Lake Simcoe Watershed) was held on September 28, 2009 by LSRCA (Ogilvie, Ogilvie and Company, 2009). The purpose of the workshop was to engage additional stakeholder groups, such as private consulting firms, conservation authorities and urban planners. It was also used as an education medium for the stormwater and urban development community and a forum to provide feedback on concerns regarding LID implementation. During the workshop, an independent facilitator moderated several discussions, including a question-and-answer period and a force field analysis session to investigate the opinions and concerns of traditional stakeholders of LID implementation as a new practice of stormwater management.

Building upon the stakeholder participation activities initiated by LSRCA for the Lake Simcoe region LID project, further research activities have been carried out to gain a deeper insight into the current challenges and concerns that exist by the stakeholders of LID implementation. To gauge these perceptions, a brief questionnaire was distributed to traditional stakeholders of stormwater management. Questions were posed to identify the opinions of specific stakeholder groups regarding LID planning for retrofit and new development cases in the Lake Simcoe watershed. This chapter presents the results of the surveys and the authors' conclusions on the responses.

\subsection{Methodology}

The goals of this study aimed to satisfy a number of objectives in the context of LID planning on a watershed level. Specifically, the research activities carried out focused on identifying:

- types of stakeholder groups represented within a watershed;

- current knowledge of LID practices possessed by stakeholder groups represented;

- LID practices that survey participants would likely be interested in implementing;

- perceptions of benefits for implementing LID practices;

- concerns for LID implementation; 
- drivers required for effective LID support;

- types of incentive programs required for effective implementation; and

- the perception of costs associated with LID implementation and maintenance.

There are numerous types of stakeholders that the LSRCA collaborates with regularly in watershed management activities. Table 19.1 shows the main identified traditional and non-traditional stakeholder groups within the watershed.

Table 19.1 Examples of stakeholder groups within the Lake Simcoe region watershed.

\begin{tabular}{ll}
\hline \multicolumn{1}{c}{ Traditional Groups } & \multicolumn{1}{c}{ Non-Traditional Groups } \\
\hline Municipal governments & Member of School Board \\
Provincial government - various departments & Community Groups and Associations \\
Federal government - various departments & Private homeowner \\
Building and Land Developers & First Nations Groups \\
Scientists (i.e., geoscientist, biologist) & Local Business Owner (i.e., restaurant, \\
Planning professional (i.e. architect, urban planner) & supermarket, etc) \\
Private consulting firm (environmental, construction) & Member of local Non-Governmental \\
Storm water professional (i.e., hydrologist, engineer) & Organizations (NGOs) \\
\hline
\end{tabular}

Due to the nature of the project and time constraints, the focus of the engagement activities was on assessing the perceptions of traditional stakeholders of stormwater management in the Lake Simcoe watershed. The assessment employed a questionnaire consisting of multiple-choice and open-ended questions which were developed based on the outcomes from the breakout sessions held at the Lake Simcoe region LID workshop.

Questionnaires were selected as the consultation method because they can gather opinions from a large group of people quickly and at a low cost. This method was particularly useful since there were a few opportunities during the project period where a large number of traditional stakeholders within the Lake Simcoe watershed were gathered. This technique is also advantageous in this case since the audience is targeted and identifiable, which facilitates measuring their attitudes. Distributing questionnaires was also the best tool to use since the purpose of engaging stakeholders in this initial planning phase is to assess the general current awareness, feelings and opinions that exist among the stakeholders in the community.

Data for this case study was collected in a three month sample period that ranged from September 28, 2009 to December 28, 2009. A summary of the three samples, the dates the data were collected, and the methodology used is shown in Table 19.2. 
Table 19.2 Key summary statistics of sample phases.

\begin{tabular}{|c|c|c|c|c|c|}
\hline Sample & Location & $\begin{array}{l}\text { Stakeholders } \\
\text { in attendance }\end{array}$ & $\begin{array}{l}\text { Surveys } \\
\text { received }\end{array}$ & $\begin{array}{l}\text { Response } \\
\text { rate }\end{array}$ & Methodology \\
\hline $\begin{array}{l}1 \text { LSRCA LID } \\
\text { workshop, Sept. } \\
28,2009\end{array}$ & $\begin{array}{l}\text { King City, } \\
\text { Ontario, } \\
\text { Canada }\end{array}$ & 71 & 46 & $65 \%$ & $\begin{array}{l}6 \text { mult. choice, } 2 \text { open } \\
\text { ended questions. }\end{array}$ \\
\hline $\begin{array}{l}2 \text { SWM } \\
\text { conference, Nov. } \\
\text { 30-Dec. 2, 2009 }\end{array}$ & $\begin{array}{l}\text { Vaughan, } \\
\text { Ontario, } \\
\text { Canada }\end{array}$ & 107 & 38 & $36 \%$ & $\begin{array}{l}11 \text { mult. choice ( } 7 \text { included } \\
\text { ranking options), } 1 \text { open } \\
\text { ended. }\end{array}$ \\
\hline $\begin{array}{l}3 \text { TRCA/CSA LID } \\
\text { training course, } \\
\text { Dec. } 8-9,2009\end{array}$ & $\begin{array}{l}\text { Mississauga, } \\
\text { Ontario, } \\
\text { Canada }\end{array}$ & 66 & 22 & $33 \%$ & Same as sample 2. \\
\hline
\end{tabular}

There were three opportunities within this sample period to assess the opinions of traditional groups of stormwater management. The first set of surveys (sample 1) was distributed at the Phase 1 workshop on September 28, 2009 (the LSRCA LID workshop). The design of this survey focused on providing a preliminary understanding of the general knowledge and concerns for LID implementation in the watershed. This initial investigation was to test the format of the questionnaire and to confirm the correct line of questioning was being applied.

The survey consisted of six multiple choice questions and two open ended questions, designed to ask about the previously stated research objectives (with the exception of the cost perception question). Each question was centred on a mix of sixteen lot, linear and area based LID technologies that could be implemented in a watershed. Lot based LID practices capture drainage at a specific point location upstream and, through a combination of techniques, manage flow and remove pollutants (Lai et al., 2007). The LID practices included of this type were soakaway pit, bioretention, dry well, rainwater harvesting, green roof, and downspout disconnection. Linear based LID practices are characterized by their narrow linear shapes adjacent to stream channels (Lai et al., 2007). The LID methods included of this type were filter strip, permeable pavement, grass channel, dry swale, infiltration trench, level spreader. Area based LID practices are land based management practices that address impervious area, land cover, and pollutant inputs (Lai et al., 2007). Roadway reduction, soil amendments, tree clusters and home clustering are LID practices of this type that were included in the survey. In total 71 questionnaires were distributed to the attendees of the LSRCA LID workshop, and $46(65 \%)$ responses were received.

The second questionnaire (sample 2) was distributed at the New Directions '09 in Stormwater Management conference (the SWM conference) held from November 30 to December 2, 2009. Based on the lessons learned 
from sample 1, improvements were made to format and question style for the surveys distributed to sample 2 participants.

The second survey consisted of eleven multiple choice questions which asked respondents to rank their opinions. One additional open ended question was provided at the end to collect general comments from the stakeholders. The survey was designed to investigate the same subject areas previously identified and was based on the same sixteen LID technologies used in sample 1. In total 107 questionnaires were distributed to the conference attendees, of which 38 (36\%) were returned.

The third sample was similar in format and type of questions to the questionnaire used in sample 2. The main difference in this third survey was that a description of the study background and research motivation was provided at the beginning of the survey for the participants' information. The sample 3 questionnaire was distributed at a two day LID training course hosted in conjunction by the Toronto Region Conservation Authority (TRCA) and the Canadian Standards Association (CSA) on December 8 and 9, 2009 (the TRCA/CSA LID training course). This course educated stormwater practitioners on LID techniques and design. There were 66 attendees at the training course, form whom 22 (33\%) completed surveys were received.

\subsection{Results and Discussions}

The responses obtained from each sample were input into the web based QuestionPro Survey Software. This online tool performed the required analysis. Where needed, a spreadsheet was used to perform additional analysis. The results for all samples will be presented and discussed according to the topics addressed in the surveys, and will more or less coincide with the order in which the research objectives are stated above. Since the questionnaires distributed in samples 2 and 3 are longer and more detailed in format than that of sample 1, a stronger emphasis may be placed on the discussion for these latter two samples. In some cases, the total number of responses reported below may not equal the sample size stated above. This is due to the respondents leaving the questions blank or filling in more than one choice.

\subsubsection{Main Stakeholder Groups Represented}

A summary of the main stakeholder groups that participated in each sample is shown in Table 19.3. 
Table 19.3 Summary of main stakeholder groups represented.

\begin{tabular}{lccc}
\hline $\begin{array}{c}\text { Main Groups in } \\
\text { Attendance }\end{array}$ & $\begin{array}{c}\text { Sample 1 (LSRCA } \\
\text { LID workshop) }\end{array}$ & $\begin{array}{c}\text { Sample 2 (SWM } \\
\text { conference) }\end{array}$ & $\begin{array}{c}\text { Sample 3 } \\
\text { (TRCA/CSA LID } \\
\text { training course) }\end{array}$ \\
\hline Municipal government & $50 \%$ & $34 \%$ & $27 \%$ \\
Conservation authority & $14 \%$ & $3 \%$ & $9 \%$ \\
Private consulting firms & $14 \%$ & $16 \%$ & $14 \%$ \\
Stormwater professionals & $3 \%$ & $34 \%$ & $32 \%$ \\
Other & $19 \%$ & $13 \%$ & $18 \%$ \\
\hline
\end{tabular}

The survey participants were asked to identify the stakeholder group that represents them the best. In the first sample, this question was an open ended question which had a low response rate. Thirty-six of the forty-six respondents $(78 \%)$ provided an answer to the question. The format of this question was modified for samples 2 and 3. Each participant was asked to select from a list of stakeholder groups to describe themself. This resulted in a $100 \%$ response rate for both samples 2 and 3 .

The analysis of the opinions or concerns according to stakeholder group will focus on these four main parties since they are identified as having the largest presence within each sample.

\subsubsection{Current Knowledge of LID Practices}

The survey participants in all three samples were asked to rank their knowledge of specific LID practices. The respondent could choose between three options to describe their familiarity with the practice. These options were:

1. "Never heard of it";

2. "Have some knowledge"; and

3. "Very familiar-currently implementing LIDs."

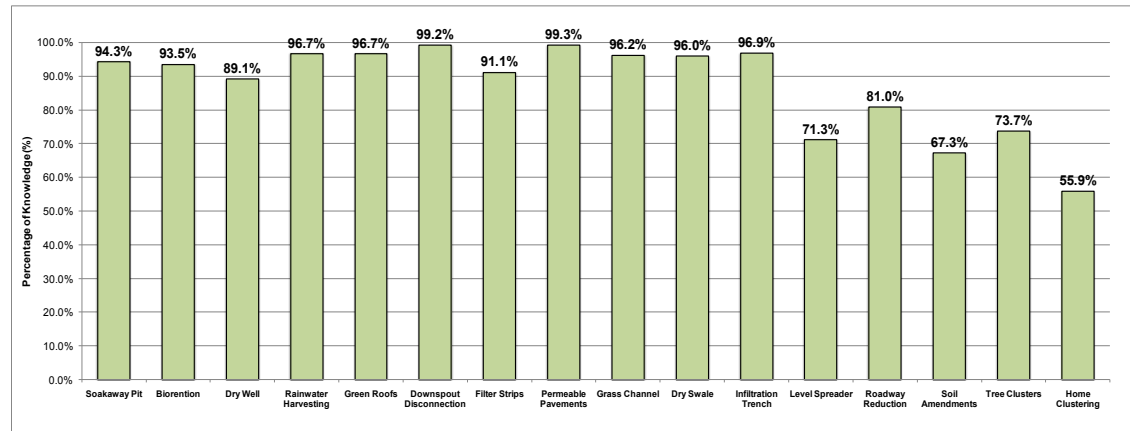

Figure 19.1 Average percentage of respondents among all samples who have some knowledge of or are very familiar with LID practices. 
Figure 19.1 displays the average results of the three sample groups. On average, over $90 \%$ of survey participants had at least some knowledge of $62.5 \%$ of the LID practices specified in the questionnaires. As shown, the current knowledge capacity among stakeholder groups is limited to lot based and linear based LID practices.

\subsubsection{LID Practices Most Likely to be Supported by Stakeholders}

The purpose of investigating this topic was to determine, based on the current knowledge capacity, which LID practices would have immediate support for implementation. The results of this question could also assist planners in determining which LID practices would need to be focused on to overcome barriers for support.

In the survey distributed to the participants in sample 1, the question asked was slightly different from samples 2 and 3. It was "Given the information presented in this workshop, which LID practices would you invest in?" In the other two samples it was "Based on your current knowledge, check off the LID practices you would most likely implement". This slight difference in questioning could have skewed the outcome. For this reason, the outcomes for sample 1 will be presented separately to samples 2 and 3 .

The results obtained for sample 1 indicated that over $95 \%$ of the respondents said they would consider investing or definitely invest in $75 \%$ of LID practices. The practices indicated to be of most interest were again mainly limited to the lot and linear based LID technologies. However, tree clusters were included as a possible LID that would be implemented in, and green roofs were excluded among the selected practices. Over $50 \%$ of the survey participants indicated they would definitely invest in rainwater harvesting, downspout disconnection, and grass channel, which are practices that are commonly implemented.

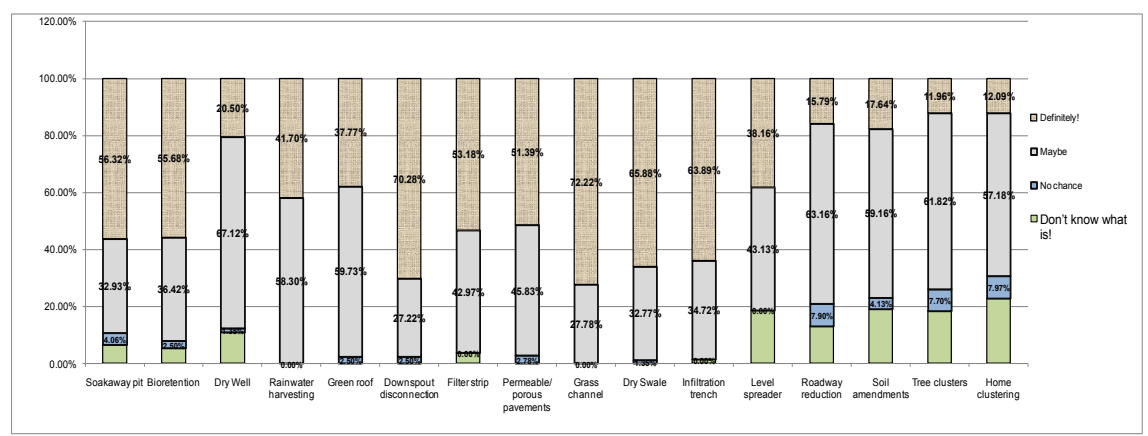

Figure 19.2 Likeliness to implement LID practices (samples 2 and 3). 
Figure 19.2 shows the average results obtained in samples 2 and 3. On average it was found that over $90 \%$ of survey participants in samples 2 and 3 would consider or definitely implement $56 \%$ of LID practices. The LID practices that had the most support for implementation were downspout disconnection, grass channel and dry swale.

Expanding further on this question, the survey participants were asked to indicate their reasons for selecting those particular LID practices they would either maybe or definitely implement. The reasons that were made available as options to select were:

1. Low capital and implementation costs;

2. Low operating and maintenance (O\&M) costs;

3. Clear existing guidelines and standards;

4. Proven case studies of effectiveness and performance;

5. Aesthetics;

6. Existing rebates and financial support programs;

7. Significant environmental benefits;

8. Reduces infrastructure required to achieve stormwater benefits; and

9. Other reasons (please specify).

The top three reasons were investigated for survey participants of sample 2 and sample 3 for each LID. It was found that the reasons that had the least amount of impact on the likeliness to implement the practices were numbers 3 and 6. The greatest reasons for LID implementation were numbers 4 and 7. This suggests that more pilot studies are needed, particularly ones that focus on technologies that have been least investigated in the past.

\subsubsection{Concerns and Barriers to LID Implementation}

Each sample group was asked to indicate for each of a given list of barriers the degree they were concerned about the barrier or felt that it prevented them from implementing LID practices (low to high concern). Table 19.4 summarizes the results of each sample group where the survey respondents selected the barrier to be of medium or high concern.

Over $95 \%$ of the participants in sample 1 chose costs, long pay-back period, lack of design guidelines or liability to be of medium and high concern. In sample 2, only $75 \%$ respondents indicated these same barriers, except for liability, to be of the same concern. In sample 3, liability and buy-in were indentified to be the barriers of medium concern. In addition to costs, long payback period and lack of design guidelines as barriers, space was indicated to be an additional concern among sample 3 respondents. 
Table 19.4 Barriers identified in each sample that were of medium and high concern.

\begin{tabular}{|c|c|c|c|}
\hline Barriers & $\begin{array}{c}\text { Sample 1 } \\
\text { (LSRCA LID } \\
\text { workshop) }\end{array}$ & $\begin{array}{c}\text { Sample } 2 \\
\text { (SWMcConference) }\end{array}$ & $\begin{array}{c}\text { Sample } 3 \\
\text { (TRCA/CSA LID } \\
\text { training course) }\end{array}$ \\
\hline Costs - capital & $92.85 \%$ & $82.86 \%$ & $89.47 \%$ \\
\hline Cost - O\&M & $97.56 \%$ & $82.86 \%$ & $88.24 \%$ \\
\hline $\begin{array}{c}\text { Time and effort to implement as } \\
\text { well as to maintain over time }\end{array}$ & * & $85.71 \%$ & $94.12 \%$ \\
\hline $\begin{array}{l}\text { Lack of design } \\
\text { guidelines/standards/policies }\end{array}$ & $100.00 \%$ & $77.78 \%$ & $82.35 \%$ \\
\hline Possible long payback period & $77.15 \%$ & $62.86 \%$ & $52.63 \%$ \\
\hline $\begin{array}{l}\text { Lack of Life-cycle-analysis and } \\
\text { economic studies }\end{array}$ & $*$ & $61.76 \%$ & $76.47 \%$ \\
\hline Space & $77.14 \%$ & $71.05 \%$ & $83.33 \%$ \\
\hline Municipal approval & $80.56 \%$ & $55.88 \%$ & $66.67 \%$ \\
\hline Liability & $85.00 \%$ & $63.89 \%$ & $68.42 \%$ \\
\hline $\begin{array}{l}\text { Buy-in (e.g. support from } \\
\text { public, gov't, etc.,) }\end{array}$ & $100.00 \%$ & $80.00 \%$ & $78.95 \%$ \\
\hline Aesthetics & $70.97 \%$ & $19.44 \%$ & $31.58 \%$ \\
\hline Winter maintenance: & $*$ & $63.89 \%$ & $72.22 \%$ \\
\hline $\begin{array}{l}\text { Lack of existing examples and } \\
\text { case studies }\end{array}$ & * & $61.11 \%$ & $62.50 \%$ \\
\hline $\begin{array}{l}\text { Minimal simulation models and } \\
\text { tools to predict performance } \\
\text { and effectiveness }\end{array}$ & $*$ & $67.57 \%$ & $75.00 \%$ \\
\hline
\end{tabular}

* Option not included in survey

As stated previously, the purpose of this question was to investigate the concerns held by each stakeholder group for implementing LID practices. Focusing the analysis on the main stakeholder groups identified in Table 19.3, the concerns were determined for each party. Sample 1 could not be included due to the open-ended format of the first question which identified the main stakeholder groups. As a result, application of the analytic tools to cross-link information provided from each question could not be applied to sample 1. The results for each main stakeholder group averaged over samples 2 and 3 are shown below in Figure 19.3.

Samples 2 and 3 identified the same barriers to be of top concern with the exception of buy-in, which was identified only by the participants in sample 2. On average, the top concern for each group was space for municipal government and conservation authority representatives; time and effort from private consulting firms; and $O \& M$ costs from stormwater professionals. 


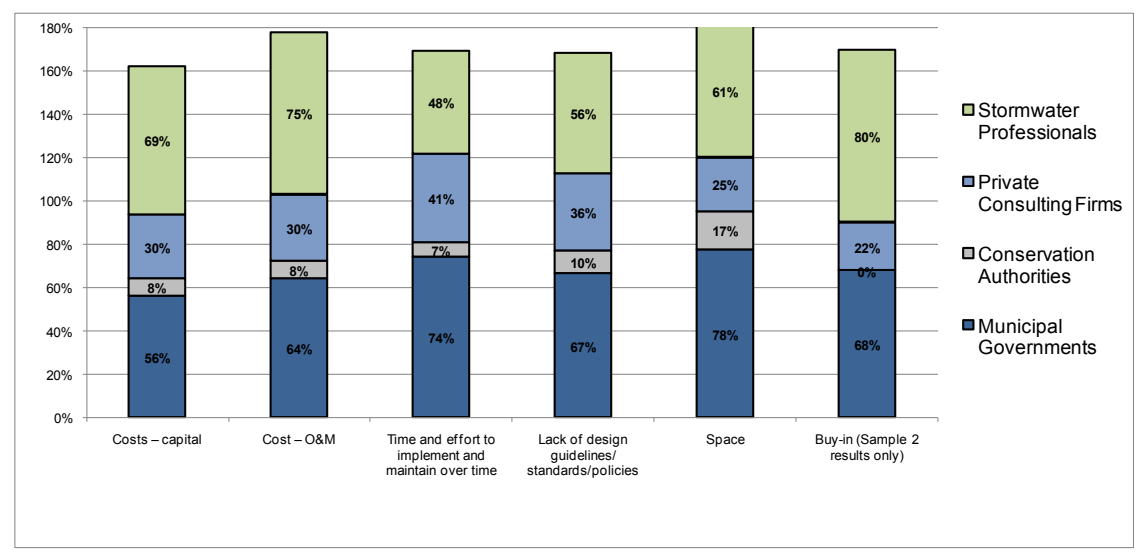

Figure 19.3 Primary concerns identified by main stakeholder groups (percent average of samples 2 and 3 ).

\subsubsection{Perception of Benefits of LID Implementation}

The survey participants were asked to identify the benefits they perceived to be associated with LID implementation from a given list of options. The list of options given in sample 1 was limited to six benefits, which included the no benefit option. This was not given as a choice in samples 2 and 3 . Figure 19.4 below shows the percentages of each benefit that the survey participants in each sample identified to be of medium and high ranking. As it is shown, the respondents in all sample groups chose aesthetics and environmental benefits to be the most advantageous aspects of implementing LID technologies. Only samples 1 and 2 identified public image to be positive. Analysing the results further by stakeholder group showed that representatives from municipal governments and conservation authorities are the groups that view public image as a high benefit to LID implementation.

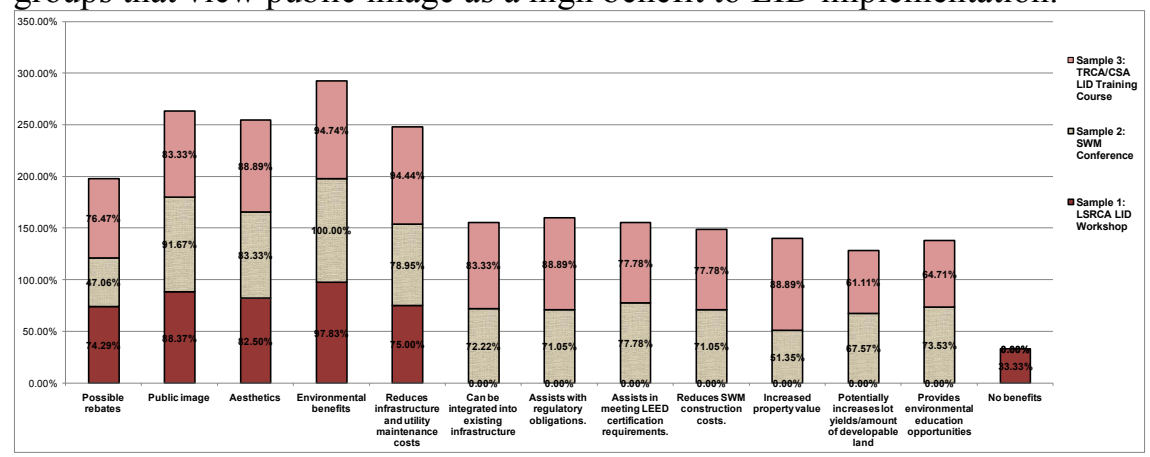

Figure 19.4 Perceptions of benefits identified by stakeholders to be of medium and high ranking. 


\subsubsection{Perceived Drivers for LID Support in the Watershed}

The perception of drivers required to support widespread LID implementation was also investigated. Survey participants were asked to select from a list all options they believed would be effective. Figure 19.5 shows the results for each sample. As shown, municipal programs and policies (e.g. rebates, by-laws, education, stormwater charges) and provincial regulations and guidelines were perceived to be the main drivers required by the survey participants in each sample group. Table 19.5 shows a breakdown of perceptions for required drivers by main stakeholder groups.

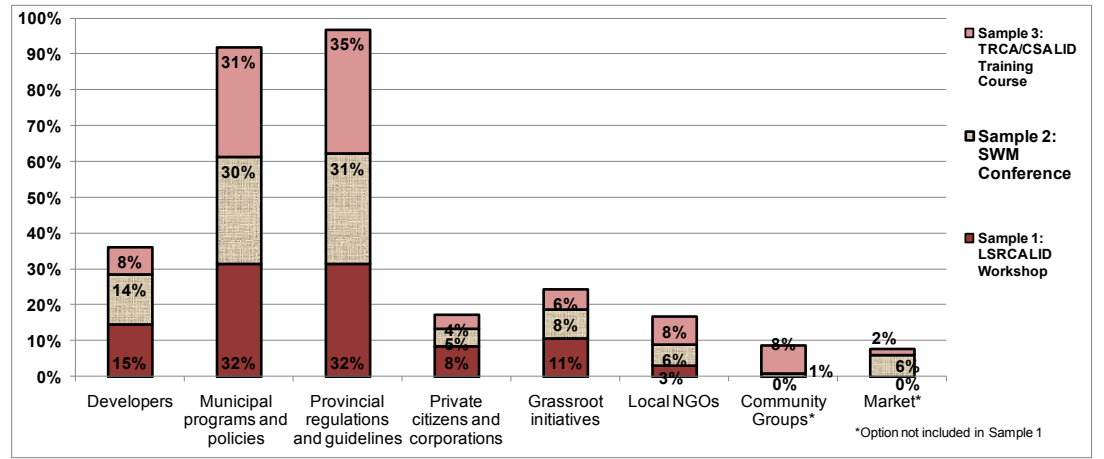

Figure 19.5 Perceived drivers for LID support in samples 2 and 3.

Table 19.5 Perception of drivers required to support LID implementation held by each stakeholder group in samples 2 and 3 .

\begin{tabular}{|c|c|c|c|c|c|c|c|c|}
\hline \multirow[b]{3}{*}{ Drivers } & \multicolumn{8}{|c|}{ Main Stakeholder Groups } \\
\hline & \multicolumn{2}{|c|}{$\begin{array}{c}\text { Municipal } \\
\text { Governments }\end{array}$} & \multicolumn{2}{|c|}{$\begin{array}{c}\text { Conservation } \\
\text { Authorities }\end{array}$} & \multicolumn{2}{|c|}{$\begin{array}{c}\text { Private Consulting } \\
\text { Firms }\end{array}$} & \multicolumn{2}{|c|}{$\begin{array}{c}\text { Stormwater } \\
\text { Professionals }\end{array}$} \\
\hline & Sample 2 & Sample 3 & Sample 2 & Sample 3 & Sample 2 & Sample 3 & Sample 2 & Sample 3 \\
\hline Developers & $19 \%$ & $9 \%$ & $0 \%$ & $0 \%$ & $0 \%$ & $0 \%$ & $9 \%$ & $8 \%$ \\
\hline $\begin{array}{l}\text { Municipal programs and } \\
\text { policies (rebates, by- } \\
\text { laws, stormwater } \\
\text { charges, etc.) }\end{array}$ & $24 \%$ & $27 \%$ & $33 \%$ & $50 \%$ & $45 \%$ & $33 \%$ & $30 \%$ & $23 \%$ \\
\hline $\begin{array}{l}\text { Provincial regulations } \\
\text { and guidelines }\end{array}$ & $30 \%$ & $27 \%$ & $33 \%$ & $50 \%$ & $36 \%$ & $67 \%$ & $33 \%$ & $38 \%$ \\
\hline $\begin{array}{l}\text { Private citizens and } \\
\text { corporations }\end{array}$ & $5 \%$ & $5 \%$ & $0 \%$ & $0 \%$ & $0 \%$ & $0 \%$ & $6 \%$ & $0 \%$ \\
\hline Grassroot initiatives & $8 \%$ & $9 \%$ & $0 \%$ & $0 \%$ & $9 \%$ & $0 \%$ & $6 \%$ & $8 \%$ \\
\hline Local NGOs & $8 \%$ & $14 \%$ & $0 \%$ & $0 \%$ & $0 \%$ & $0 \%$ & $6 \%$ & $8 \%$ \\
\hline Community Groups & $0 \%$ & $9 \%$ & $0 \%$ & $0 \%$ & $0 \%$ & $0 \%$ & $3 \%$ & $8 \%$ \\
\hline $\begin{array}{l}\text { Market }- \text { Strong desire } \\
\text { for environmental } \\
\text { responsibility }\end{array}$ & $5 \%$ & $0 \%$ & $33 \%$ & $0 \%$ & $9 \%$ & $0 \%$ & $6 \%$ & $8 \%$ \\
\hline
\end{tabular}

In sample 2, municipal governments and stormwater professionals both identified developers as an additional driver whereas conservation authori- 
ties and private consulting firms saw the market driving the uptake of LID principles. For sample 3, municipal governments and stormwater professionals were the only stakeholder groups to identify additional drivers. Municipal governments selected local NGOs as the next top driver, whereas stormwater professionals equally weighted developers, grass root initiatives, local NGOs and community groups, and the market as additional drivers. Conservation authorities and private consulting firms perceived only the two main drivers as those required to ensure widespread LID support.

\subsubsection{Incentive Programs Required for Effective LID Implementation}

Figure 19.6 shows the responses by survey participants in each sample group on their opinion of incentive programs that should be in place to support LID implementation. On average, reduced requirements for stormwater management, streamlined approvals (e.g. accelerated reviews for site plans), and bonuses if LID practices are used that accomplish stormwater management goals (e.g. municipal rebate, increased floor area ratio), were selected among all participants in each group as the top incentive programs required to gain widespread support for LID principles.

A breakdown of required incentive programs perceived by the main stakeholder groups is shown in Table 19.6. As shown in sample 2, while the top incentive programs selected by all stakeholder groups surveyed were the incentive programs given above, not all main stakeholder groups identified selected these programs. For example, in addition to the top incentive programs, municipal governments also selected recognition programs and grants for funding LID projects. Conservation authorities did not see bonuses as the top incentive, but placed equal weighting on reduced requirements for stormwater management and tax credits. Private consulting firms did not select bonuses or credits for stormwater utilities as an incentive program; rather they selected reduced requirements for stormwater management and tax credit for qualifying LID projects to be better suited incentive programs. Stormwater professionals, unlike the other main groups, chose reduced requirements for stormwater management in addition to bonuses and credits for stormwater utility fees. Similarly for sample 3, municipal governments selected recognition programs, streamlined approvals and grants for funding as the top incentive programs to be in place. Conservation authorities saw bonuses as the top incentive, and equally weighted reduced requirements for stormwater management, streamlined approvals and reduced fees. Stormwater professionals and private consulting firms identified with two out of the three identified top incentives. Private consulting firms saw reduced requirements for stormwater management as being an additional means of 
motivation. Stormwater professionals equally weighted six out of the eight programs, with the incentives of creating a recognition program and the availability of tax credits being given slightly higher value than the other selected incentives.

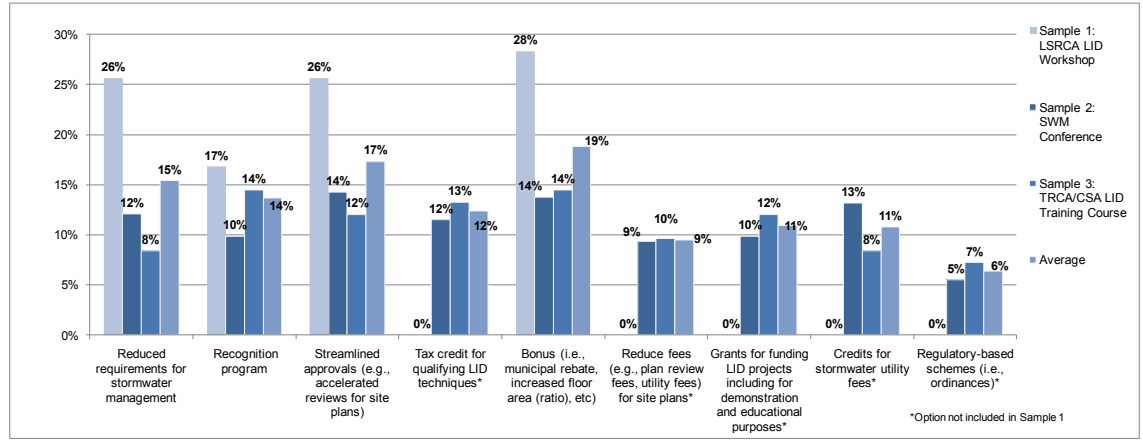

Figure 19.6 Incentive programs identified by survey participants in samples 2 and 3.

Table 19.6 Perception of incentive programs required for effective LID support by main stakeholder groups in samples 2 and 3 .

\begin{tabular}{|c|c|c|c|c|c|c|c|c|}
\hline \multirow[b]{3}{*}{ Drivers } & \multicolumn{8}{|c|}{ Main Stakeholder Groups } \\
\hline & \multicolumn{2}{|c|}{$\begin{array}{l}\text { Municipal } \\
\text { Governments }\end{array}$} & \multicolumn{2}{|c|}{$\begin{array}{l}\text { Conservation } \\
\text { Authorities }\end{array}$} & \multicolumn{2}{|c|}{$\begin{array}{c}\text { Private Consulting } \\
\text { Firms }\end{array}$} & \multicolumn{2}{|c|}{$\begin{array}{l}\text { Stormwater } \\
\text { Professionals }\end{array}$} \\
\hline & Sample 2 & Sample 3 & Sample 2 & Sample 3 & Sample 2 & Sample 3 & Sample 2 & Sample 3 \\
\hline $\begin{array}{l}\text { Reduced requirements } \\
\text { for SWM }\end{array}$ & $6 \%$ & $5 \%$ & $25 \%$ & $20 \%$ & $15 \%$ & $17 \%$ & $15 \%$ & $11 \%$ \\
\hline Recognition program & $13 \%$ & $20 \%$ & $0 \%$ & $0 \%$ & $11 \%$ & $8 \%$ & $11 \%$ & $15 \%$ \\
\hline Streamlined approvals & $14 \%$ & $20 \%$ & $25 \%$ & $20 \%$ & $15 \%$ & $8 \%$ & $14 \%$ & $7 \%$ \\
\hline $\begin{array}{l}\text { Tax credit for qualifying } \\
\text { LID techniques }\end{array}$ & $11 \%$ & $10 \%$ & $25 \%$ & $0 \%$ & $15 \%$ & $17 \%$ & $9 \%$ & $15 \%$ \\
\hline $\begin{array}{l}\text { Bonuses (i.e. municipal } \\
\text { rebate) }\end{array}$ & $13 \%$ & $10 \%$ & $0 \%$ & $40 \%$ & $7 \%$ & $17 \%$ & $18 \%$ & $11 \%$ \\
\hline $\begin{array}{l}\text { Reduce fees (e.g. plan } \\
\text { review fees) }\end{array}$ & $10 \%$ & $5 \%$ & $0 \%$ & $20 \%$ & $11 \%$ & $8 \%$ & $6 \%$ & $11 \%$ \\
\hline $\begin{array}{l}\text { Grants for funding LID } \\
\text { projects }\end{array}$ & $13 \%$ & $15 \%$ & $0 \%$ & $0 \%$ & $4 \%$ & $8 \%$ & $8 \%$ & $11 \%$ \\
\hline $\begin{array}{l}\text { Credits for stormwater } \\
\text { utility fees }\end{array}$ & $13 \%$ & $10 \%$ & $25 \%$ & $0 \%$ & $11 \%$ & $8 \%$ & $15 \%$ & $11 \%$ \\
\hline $\begin{array}{l}\text { Regulatory based } \\
\text { schemes (i.e. } \\
\text { ordinances, policies) }\end{array}$ & $6 \%$ & $5 \%$ & $0 \%$ & $0 \%$ & $11 \%$ & $8 \%$ & $3 \%$ & $7 \%$ \\
\hline
\end{tabular}

\subsubsection{Perception of Costs for Implementing and Maintaining LID}

Stakeholders at the LSRCA LID workshop expressed, as well as through these questionnaires, concerns related to the costs associated to installing and maintaining LID technologies. The final research objective was to inves- 
tigate the perceptions of associated costs to LID implementation. Survey participants in samples 2 and 3 were asked to rank their opinion of costs connected to each LID practice. Figure 19.7 displays the distribution of perceptions for each LID technology believed to be of high costs according to the survey participants of samples 2 and 3 .

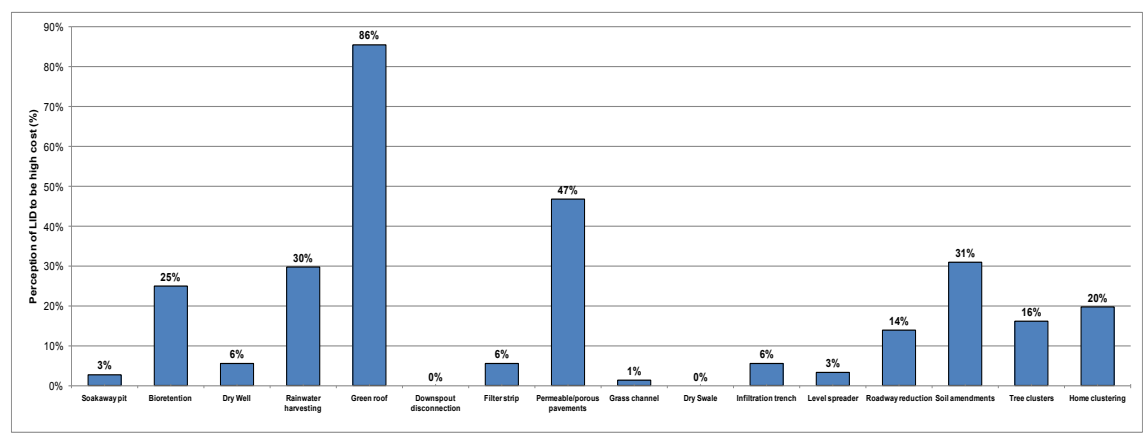

Figure 19.7 Perception of LID practices to be a high cost for implementation and maintenance (\% average of samples 2 and 3 ).

As shown, the implementation and maintenance costs associated with green roofs, permeable pavements, and soil amendments were perceived on average to incur the highest expenses. Despite these perceived costs, green roofs and permeable pavements were also identified by survey participants in these sample groups as LID practices they are very familiar with and would likely invest in. While soil amendments were identified in this question to be a practice of high cost in the opinion of the respondents, it was also selected as a practice with that many of the participants have very little knowledge and one that would likely not be considered for investment.

\subsection{Conclusions and Recommendations}

The results of this study provided a greater insight into the opinions and concerns of traditional stakeholders of stormwater management within the Lake Simcoe watershed. From the outcomes of the questionnaires distributed on three occasions in the period from September 28, 2009 to December 9, 2009 , it was found that the main stakeholder groups among the participants were representatives from municipal governments, conservation authorities, private consulting firms, and stormwater professionals. Over $90 \%$ of the survey participants indicated they had at least some knowledge of $62.5 \%$ of LID practices specified in the questionnaires. Based on this current knowledge capacity, over $90 \%$ of the respondents in all samples indicated 
they would at least consider investing in over half of the LID technologies listed. However, the stakeholder groups that responded voiced a number of concerns regarding implementation. Some of the major barriers that were identified as preventing these groups from full scale support are space, time and effort required, as well as capital and O\&M costs. The issue of associated costs was investigated further by probing the participants regarding their perception of costs. LID practices such as green roofs, permeable pavements and soil amendments were perceived to have the highest implementation and maintenance costs. Despite these barriers, the survey participants did recognize the benefits that are associated with LID application. The participants indicated that aesthetics and environmental benefits were the most advantageous aspects of implementing these sustainable technologies. Opinions gathered from the respondents showed that the assistance of drivers such as municipal programs and policies, as well as incentive programs such as reducing the requirements for stormwater management and streamlined approvals, will encourage widespread support for LID principles.

While further investigations into the opinions held by traditional stakeholders of stormwater management of LID will be required, the results of this study provided an initial insight into how these results can be applied to support effective widespread LID implementation. For example, based on the outcomes of the surveys, strategies for buy-in can be developed, possibly directed towards the main stakeholder groups that were present in all three samples. Guidelines and manuals can be created, particularly for specific LID practices. The LID practices that respondents were the most familiar with are practices that have existing manuals present. The results can also assist in the development of policies and programs, provide direction for subwatershed planning, as well as identify further studies required by stakeholders for implementation (e.g. performance case studies and feasibility studies).

Based on the outcomes of this research, existing case studies, and the nature of LID technologies to control stormwater at source and through conveyance systems, the requirement to involve a range of groups representing various interests, socially, technically, and politically, is essential for effective LID application. It is believed that as a result of taking a more holistic approach early in the LID planning process, stronger support from all appropriate actors of stormwater management will be achieved throughout the project. Not only will a greater understanding into these identified groups' capacity in applying LID technologies within the watershed be achieved, but also insight into the challenges that maybe encountered in future implementation. Engaging stakeholders throughout the planning, decision making, and project phases could lead to minimizing a significant 
number of barriers, facilitating uptake of LID principles, encouraging widespread implementation, and ensuring support in the long-term. Without the support of all affected groups effective LID implementation will not occur.

\section{Acknowledgments}

The authors would like to acknowledge the LSRCA, the Canadian Standards Association (CSA), and organizers of the New Directions ' 09 in Stormwater Management conference for providing opportunities to consult with stakeholders for this research study. In addition, we thank LSRCA for its financial contribution to this project.

\section{References}

Adams, L.W., Dove, L.E. and Leedy, D.L. (1984). Public Attitudes toward Urban Wetlands for Stormwater Control and Wildlife Enhancement. Wildlife Society Bulletin, 12 (3), pp. 299-303. Retrieved from http://www.jstor.org/stable/3781998.

Apostolaki, S., Jefferies, C. and Wild, T. (2006). The social impacts of stormwater management techniques. Water Practice and Technology, 1(1). doi:10.2166/WPT.2006009.

Beierle, T.C. (1999). Using social goals to evaluate public participation in environmental decisions. Review of Policy Research, 16( 3-4), 75-103. doi: 10.1111/j.15411338.1999.tb00879.x

Beierle, T.C. and Konisky, D.M. (2000). Values, Conflict, and Trust in Participatory Environmental Planning. Journal of Policy Analysis and Management, 19(4), pp. 587-602. Retrieved from http://www.jstor.org/stable/3325576.

Brown, R. R. (2005). Impediments to integrated urban stormwater management: The need for institutional reform. Environmental Management, 36 (3), 455-468. doi: 10.1007/s00267-004-0217-4.

Brown, R.R. and Clarke, J. (2007) The transition towards water sensitive urban design: the story of Melbourne, Australia, Report No. 07/ 01, Facility for Advancing Water Biofiltration, Monash University, June 2007, ISBN 978-0-9803428-0-2

Brown, R. and Farrelly, M. (2008). Sustainable Urban Stormwater Management in Australia: Professional Perceptions on Institutional Drivers and Barriers. In Ashley, R.M. (Ed) Proceedings of the 11th International Conference on Urban Drainage, Edinburgh, Scotland, 31st August - 5th September 2008. Retrieved from http://www.urbanwatergovernance.com/publications.html.

Credit Valley Conservation (CVC), and Toronto and Region Conservation Authority (TRCA). (2009). Low impact development stormwater management manual (Draft ed.). Retrieved from http://www.sustainabletechnologies.ca/.

Dietz, M.E. (2007). Low impact development practices: A review of current research and recommendations for future directions. Water, Air, Soil Pollution, 186, 351 - 363. doi: 10.1007/s11270-007-9484-z.

Dolnicar, S. and Schäfer, A.I., (2009). Desalinated versus recycled water: Public perceptions and profiles of the accepters. Journal of Environmental Management, 90, 888900. doi:10.1016/j.jenvman.2008.02.003 
Ellis, J.B., Deutsch, J.C., Legret, M., Martin, C., Revitt, D. M., Scholes, L. and Zimmerman, U. (2006). The DayWater decision support approach to the selection of sustainable drainage systems: A multi-criteria methodology for BMP decision makers. Water Practice and Technology, 1 (1). doi: 10.2166/WPT.2006002.

Ellis, J.B., Deutsch, J.C., Mouchel, J.M., Scholes, L. and Revitt, M.D. (2004). Multicriteria decision approaches to support sustainable drainage options for the treatment of highway and urban runoff. Science of the Total Environment, 334 - 335, 251 - 260, doi:10.1016/j.scitotenv.2004.04.066.

Elliott, A.H., and Trowsdale, S.A. (2006). A review of models for low impact urban stormwater drainage. Environmental Modeling and Software, 22, 394-405, doi:10.1016/j.envsoft.2005.12.005.

Farahbakhsh, K., Despins, C. and Leidl, C. (2008). Evaluating the feasibility and developing design requirements and tools for large-scale rainwater harvesting in Ontario. Prepared for the Canadian Mortgage and Housing Corporation [CMHC] by the University of Guelph.

Gilroy, K.L, and McCuen R.H. (2009). Spatio-temporal effects of low impact development practices. Journal of Hydrology, 367, 228 - 236. doi:10.1016/j.jhydrol.2009.01.008.

Graham, P., Maclean, L., Medina, D., Patwardhan, A. and Vasarhelyi, G. (2004). The role of water balance modeling in the transition to low impact development. Water Quality Research Journal of Canada, 39 (4), 331-342. Retrieved from http://www.cawq.ca/cgi-bin/journal/display.cgi?language=english\&pk_journal=68.

Government of British Columbia. (2002). Stormwater planning: A guidebook for British Columbia. Retrieved from http://www.env.gov.bc.ca/epd/epdpa/mpp/stormwater/guidebook/pdfs/stormwater.pdf

Hellstrom, D., Jeppsson, U. and Karrman, E. (2000). A framework for systems analysis of sustainable urban water management. Environmental Impact Assessment Review, 20 (3), 311-321. doi:10.1016/S0195-9255(00)00043-3.

Hwang, A. H.-S., Valeo, C. and Draper, D. (2006). Public perceptions and attitudes toward stormwater recycling for irrigation. Canadian Water Resources Journal, 31(3), 185-196. doi:10.4296/cwrj3103185

Irvin, R.A. and Stansbury, J. (2004). Citizen Participation in Decision Making: Is It Worth the Effort?. Public Administration Review, 64(1), 55-65. Retrieved from http://www.jstor.org/stable/3542626.

Larson, K.L. and Lach, D. (2007). Participants and non-participants of place-based groups: An assessment of attitudes and implications for public participation in water resource management. Journal of Environmental Management, 88, 817-830. doi:10.1016/j.jenvman.2007.04.008.

Lai, F., Dai, T., Zhen, J., Riverson, J., Alvi, K. and Shoemaker, L. (2007). Sustain - An EPA BMP process and placement tool for urban watershed. Fairfax, VA : Water Environment Federation.

Li, J., Banting, D., Joksimovics, D., Lawson, S., Hahn, K. and Ahmed, N. (2009). Evaluation of Low Impact Development Stormwater Technologies and Water Reuse Options for the Lake Simcoe Regions Phase 1 Draft Report. Toronto: Ryerson University.

Lloyd, S., Wong, T. H.F. and Chesterfield, C.J. (2002). Water sensitive urban design - A stormwater management perspective. Melbourne: Melbourne Water Corporation Cooperative Research Centre for Catchment. 
Maguire, L.A. and Lind, E.A. (2003). Public participation in environmental decisions: stakeholders, authorities and procedural justice. International Journal of Global Environmental Issues, 3(2), 133-148. doi: 10.1504/IJGENVI.2003.003861.

Marks J.S., Martin, B. and Zadoroznyj, M. (2006). Acceptance of water recycling in Australia: national baseline data. Water, March, 151-157.

Makropoulos, C.K., Natsis, K., Liu, S., Mittas, K. and Butler, D. (2008). Decision support for sustainable option selection in integrated urban water management. Environmental Modeling and Software, 23, 1448-1460. doi:10.1016/j.envsoft.2008.04.010.

McKissock, G., D’Arcy, B.J., Wild, T.C., Usman, F. and Wright, P.W. (2003). An evaluation of SUDS guidance in Scotland. Diffuse Pollution Conference Dublin 2003

Mustajoki, J., Hamalainen, R.P. and Marttunen, M. (2004) Participatory multicriteria decision analysis with Web-HIPRE: a case of lake regulation policy. Environmental Modeling and Software, 19, 537-547. doi:10.1016/j.envsoft.2003.07.002.

Ogilvie, Ogilvie and Company. (2009). Phase 1 Workshop Stormwater Management Strategies for Uncontrolled Urban Areas in the Lake Simcoe Watershed - Facilitator Summary. King City: Ogilvie, Ogilvie and Company.

Prince George's County Government. (1999). Low-impact development design strategies: An integrated design approach. Retrieved from http://www.lowimpactdevelopment.org/pubs/LID_National_Manual.pdf.

QuestionPro Survey Software. (2009). Seattle, WA: Survey Analytics LLC.

Roy, A.H., Wenger, S.J., Fletcher, T.D., Walsh, C.J., Ladson, A.R., Shuster, W.D., Thurston, H.W. and Brown, R.R. (2008). Impediments and Solutions to Sustainable, Watershed-Scale Urban Stormwater Management: Lessons from Australia and the United States. Environmental Management, 42,344-359. doi: 10.1007/s00267-0089119-1

Southeast Michigan Council of Governments (SEMCOG). (2008). Low impact development manual for Michigan: A design guide for implementers and reviewers.

Retrieved from http://library.semcog.org/InmagicGenie/DocumentFolder/LIDManualWeb.pdf.

Tran, K.C., Euan, J. and Isla, M.L. (2002). Public perception of development issues: impact of water pollution on a small coastal community. Ocean and Coastal Management, 45, 405-420. doi:10.1016/j.ocecoaman.2006.02.005. 